\title{
Seasonal changes in the accessory reproductive system and plasma testosterone levels of the male tammar wallaby, Macropus eugenii, in the wild
}

\author{
R. W. Inns* \\ Department of Zoology, University of Adelaide, South Australia
}

\begin{abstract}
Summary. Reproductive organs and plasma testosterone levels were measured every 2 months from May 1975 to April 1977. Male wallabies became sexually mature at 18-20 months of age when the testes began to enlarge, the seminiferous tubules opened and increased in diameter, and spermatozoa first appeared. The weight of the testes and epididymides of sexually mature wallabies did not show any annual changes but there was a significant increase in the size of the prostate and Cowper's glands and in peripheral testosterone concentrations during the breeding season. These results support suggestions that the males respond directly to the breeding condition of the females.
\end{abstract}

\section{Introduction}

Despite the considerable amount of information now available on the reproductive physiology of female macropodid marsupials (Sharman \& Berger, 1969; Tyndale-Biscoe, Hearn \& Renfree, 1974; Tyndale-Biscoe, 1980) little attention has been paid to the male. The anatomy and some aspects of the physiology of the male marsupial reproductive system have been described by Biggers (1966). Setchell \& Carrick (1973) reported on the pattern of spermatogenesis in several species of Australian marsupials while Rodger \& Hughes (1973) studied the anatomy, histology and histochemistry of the accessory reproductive organs. Subsequent reviews by Setchell (1977) and Rodger (1978) have summarized the present state of knowledge in these areas.

For the macropodids, field studies have shown that the red kangaroo (Macropus rufus) and the euro (Macropus robustus) are fertile throughout the year as no changes were observed in testicular size or spermatogenic activity (Frith \& Sharman, 1964; Newsome, 1965; Sadleir, 1965). This correlated with the continuous breeding pattern of the females.

The tammar wallaby (Macropus eugenii) has a well defined breeding season with most young being born in late January and early February (Andrewartha \& Barker, 1969). There is a postpartum oestrus, and fertilization results in the formation of a dormant blastocyst (Berger, 1966; Berger \& Sharman, 1969). This blastocyst remains quiescent for up to 11 months, or until just after the summer solstice in late December, unless reactivated earlier by loss of the pouch young between January and June. Despite this seasonal breeding cycle Hearn (1975) did not find any difference between the breeding and non-breeding season in the weights of the testes, epididymides, prostate or Cowper's glands of captive wallabies. This was surprising as the brush-tailed possum (Trichosurus vulpecula), which is also a seasonal breeder, shewed an increase in the size of the accessory

* Present address: CSIRO Division of Land Resources Management, Private Bag, P.O., Deniliquin, New South Wales 2710, Australia. 
reproductive organs in the breeding season although testicular and epididymal weights did not change (Gilmore, 1969).

This paper describes the results obtained from a 2-year study of the male tammar wallaby to determine whether seasonal changes in the reproductive system take place in the wild.

\section{Materials and Methods}

Collection of samples. Animals were collected at 2-monthly intervals from May 1975 to April 1977. They were shot at night after they had emerged from scrub to feed on farmland. Immediately after the animals had been shot, blood samples were collected by cardiac puncture and kept on ice in heparinized tubes until later, when they were centrifuged for collection of plasma. Plasma samples were stored frozen. Body weights were measured and the teeth examined for age determination (Inns, 1982). The right testis and epididymis, the prostate gland and the 3 pairs of Cowper's glands were dissected out, fixed in formol-acetic- $80 \%$ alcohol $(1: 1: 18$ by vol.), weighed 10 days after fixing and then stored in $80 \%$ alcohol. Testicular and epididymal weights relate to organs on the right side only; the whole prostate gland and the 3 Cowper's glands on both sides of the body were weighed.

Testis biopsies were also taken from live animals caught in Flinders Chase National Park, Kangaroo Island. The biopsy sample was taken by first clipping fur from the surface of the right testis, making a small puncture in the scrotum and tunica with a No. 11 scalpel blade and squeezing out a small amount of tissue which was fixed in formol-acetic-alcohol.

Histology. After weighing, small pieces of testis, epididymis, prostate gland and paired Cowper's glands were dissected out for histological examination. Tissues were dehydrated via graded alcohols, cleared in benzene and embedded in paraffin wax. Sections were cut at $7 \mu \mathrm{m}$ and routinely stained with Ehrlich's haematoxylin and eosin. The periodic acid-Schiff reaction, following the method of Drury \& Wallington (1967), was used to detect the presence of mucopolysaccharides in prostate and Cowper's gland tissue. Measurements of testis tubule diameters were made with a calibrated micrometer eyepiece.

Testosterone assay. Concentrations of testosterone in plasma were measured by a radioimmunoassay procedure using an antiserum raised to testosterone-3-(O-carboxymethyl) oxime-BSA (prepared by Dr R. I. Cox, Division of Animal Production, CSIRO, Blacktown, N.S.W., Australia). The antiserum has a low cross-reactivity with a wide range of steroids, with the exception of $5 \alpha-$

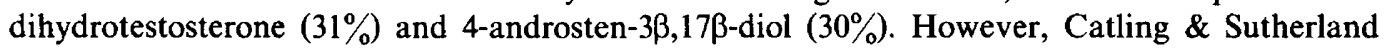
(1980) reported that the major plasma androgen of the tammar wallaby was testosterone. The sensitivity of the assay was $10 \mathrm{pg} /$ tube and the intra- and inter-assay coefficients of variation were 7 and $11 \%$ respectively.

\section{Results}

Sexual maturity of males. Male tammar wallabies reached sexual maturity at 18-20 months of age when rapid growth of the testes occurred. Testicular weight increased with body weight and age, although after 3 years of age testicular weight remained fairly constant (Text-fig. 1). Spermatogenesis began at about 18 months of age when the seminiferous tubules increased in diameter and developed a lumen (Text-fig. 1). By 2 years of age the seminiferous tubules were fully distended and contained spermatozoa. The diameter of the tubules showed virtually no further increase after 2 years of age.

Seasonal changes. To test for significant seasonal changes in the reproductive organs and plasma testosterone concentration each set of data was analysed by means of a one-way analysis of variance. The results of these tests are summarized in Table 1. 


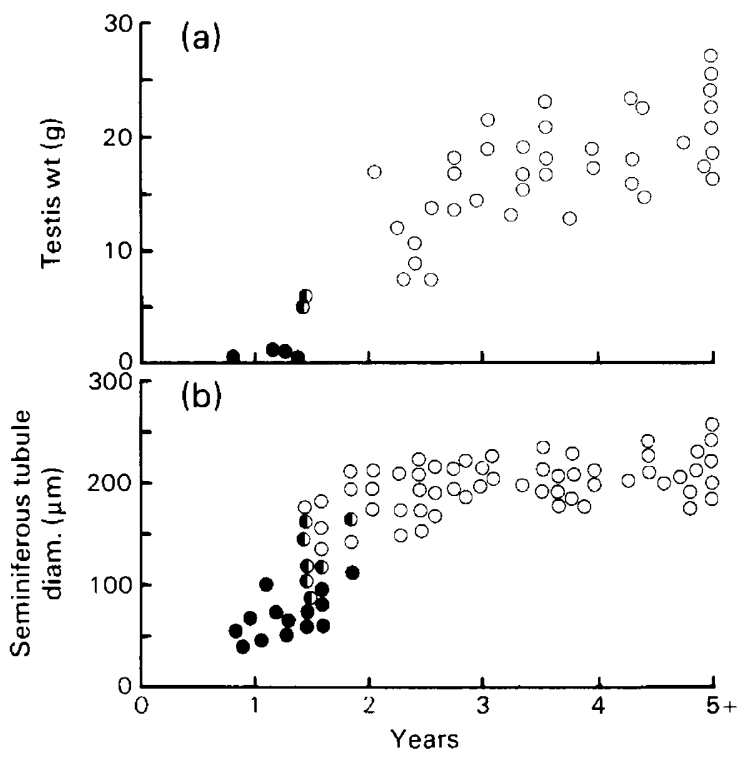

Text-fig. 1. Relationship between the age of wallabies and (a) testicular weight and (b) seminiferous tubule diameter. - Closed tubules with no spermatozoa present; $\boldsymbol{D}$, partly open tubules in which spermatogenesis has begun; $O$, open tubules with spermatozoa present.

Table 1. Analysis of variance for seasonal changes in male reproductive organs and plasma testosterone levels

\begin{tabular}{lll}
\hline & \multicolumn{1}{c}{$* 1975-1976$} & \multicolumn{1}{c}{$1976-1977$} \\
\hline Testis wt $(\mathrm{g})$ & $\mathrm{F}_{(7,72)}=0.400, \mathrm{~N} . \mathrm{S}$. & $\mathrm{F}_{(6,68)}=1.694, \mathrm{~N} . \mathrm{S}$. \\
Seminiferous tubule diam. $(\mu \mathrm{m})$ & $\mathrm{F}_{(7,72)}=1.238, \mathrm{~N} . \mathrm{S}$. & $\mathrm{F}_{(6,66)}=2.024$, N.S. \\
Epididymis wt $(\mathrm{g})$ & $\mathrm{F}_{(7,72)}=1.273, \mathrm{~N} . \mathrm{S}$. & $\mathrm{F}_{(6,68)}=1.010$, N.S. \\
Prostate gland wt $(\mathrm{g})$ & $\mathrm{F}_{(7,72)}=28.797, P<0.001$ & $\mathrm{~F}_{(6,68)}=16.528, P<0.001$ \\
Cowper's glands wt $(\mathrm{g})$ & $\mathrm{F}_{(5,44)}=8.026, P<0.001$ & $\mathrm{~F}_{(6,60)}=6.461, P<0.001$ \\
Testosterone conc. $(\mathrm{ng} / \mathrm{ml})$ & $\mathrm{F}_{(4,41)}=17.555, P<0.001$ & $\mathrm{~F}_{(6,49)}=6.366, P<0.001$ \\
\hline
\end{tabular}

* For testis weight, testis tubule diameter, epididymis weight and prostate gland weight the analysis of results for the 2 years was from May 1975 to May 1976, and May 1976 to April 1977. For Cowper's glands weight analysis was from September 1975 to May 1976 and May 1976 to April 1977. For testosterone concentration analysis was from October 1975 to May 1976 and May 1976 to April 1977.

N.S., not significant at $5 \%$ level.

There were no seasonal changes in testis weight, seminiferous tubule diameter or epididymis weight $(P>0.05)$ (Text-fig. 2). Spermatogenesis occurred throughout the year and spermatozoa were always present in the seminiferous tubules and epididymis.

The prostate gland of the tammar wallaby is carrot-shaped and located at the posterior end of the body cavity within the pelvic region. The gland consists of glandular tissue surrounded by the smooth muscle coat of the membranous urethra. The vasa deferentia enter at the anterior end of the gland just below where the bladder and the ureters join the urethra. The gland can be divided into three segments, referred to as anterior, central and posterior segments. The structure and histochemistry of the prostate gland have been described by Rodger \& Hughes (1973). The prostate 


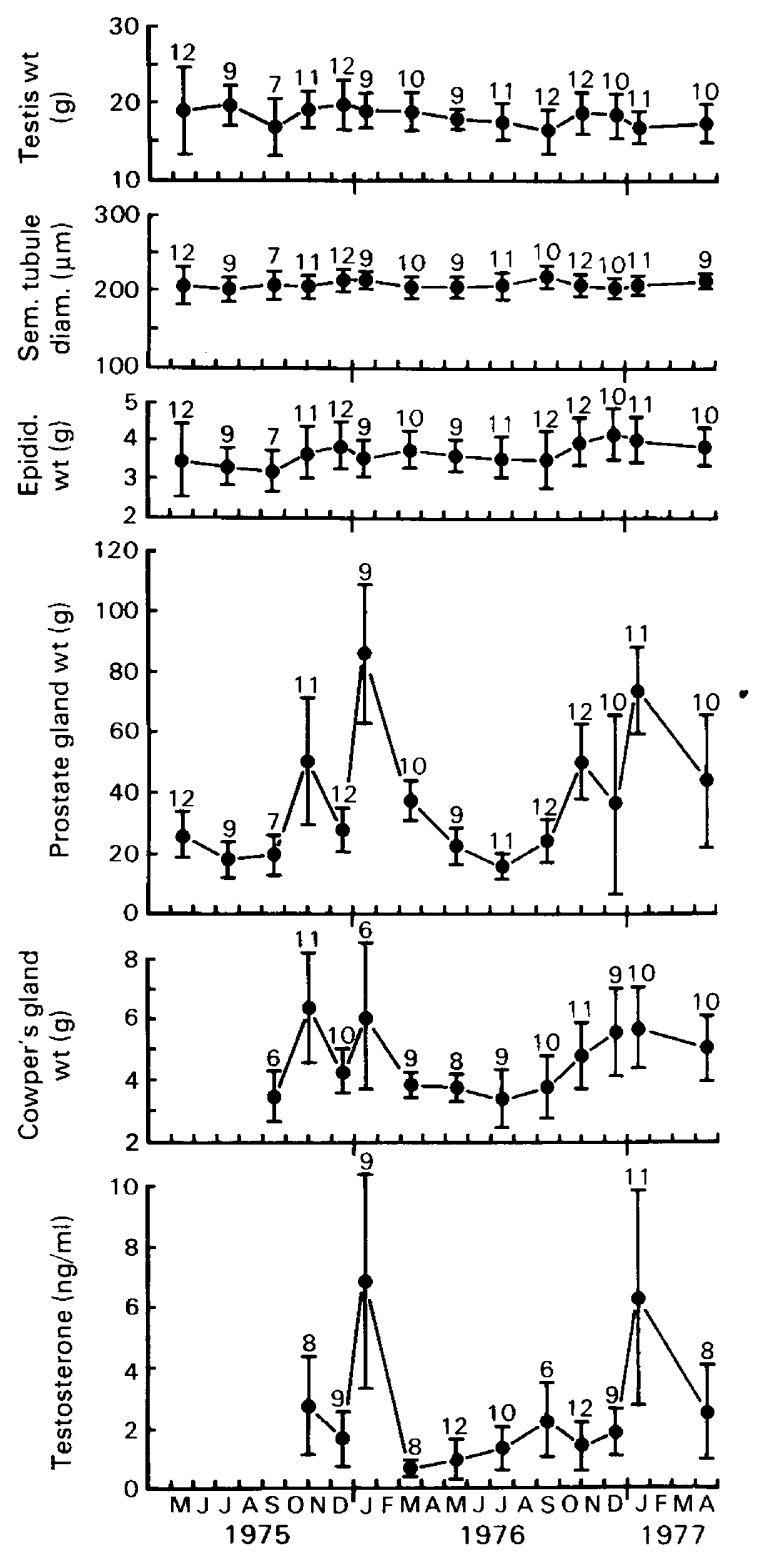

Text-fig. 2. Mean \pm s.d. values for various characteristics of male tammar wallabies over 2 years. The no. of animals in each sample is indicated.

gland showed a significant increase in size $(\mathrm{P}<0.001)$ in the breeding season (Text-fig. 2$)$. The size and appearance of the tubules in each segment of the prostate gland also changed between the breeding and non-breeding season. In the non-breeding season the tubules appeared to be smaller in diameter and the height of the epithelium lining the tubules was reduced (P1. 1, Figs 1-6). However, periodic acid-Schiff staining showed that mucopolysaccharides were present throughout the year.

The three pairs of Cowper's glands in the wallaby are located posterior to and on either side of the prostate gland. The glands are bulbous structures and are joined to the base of the urethra by 

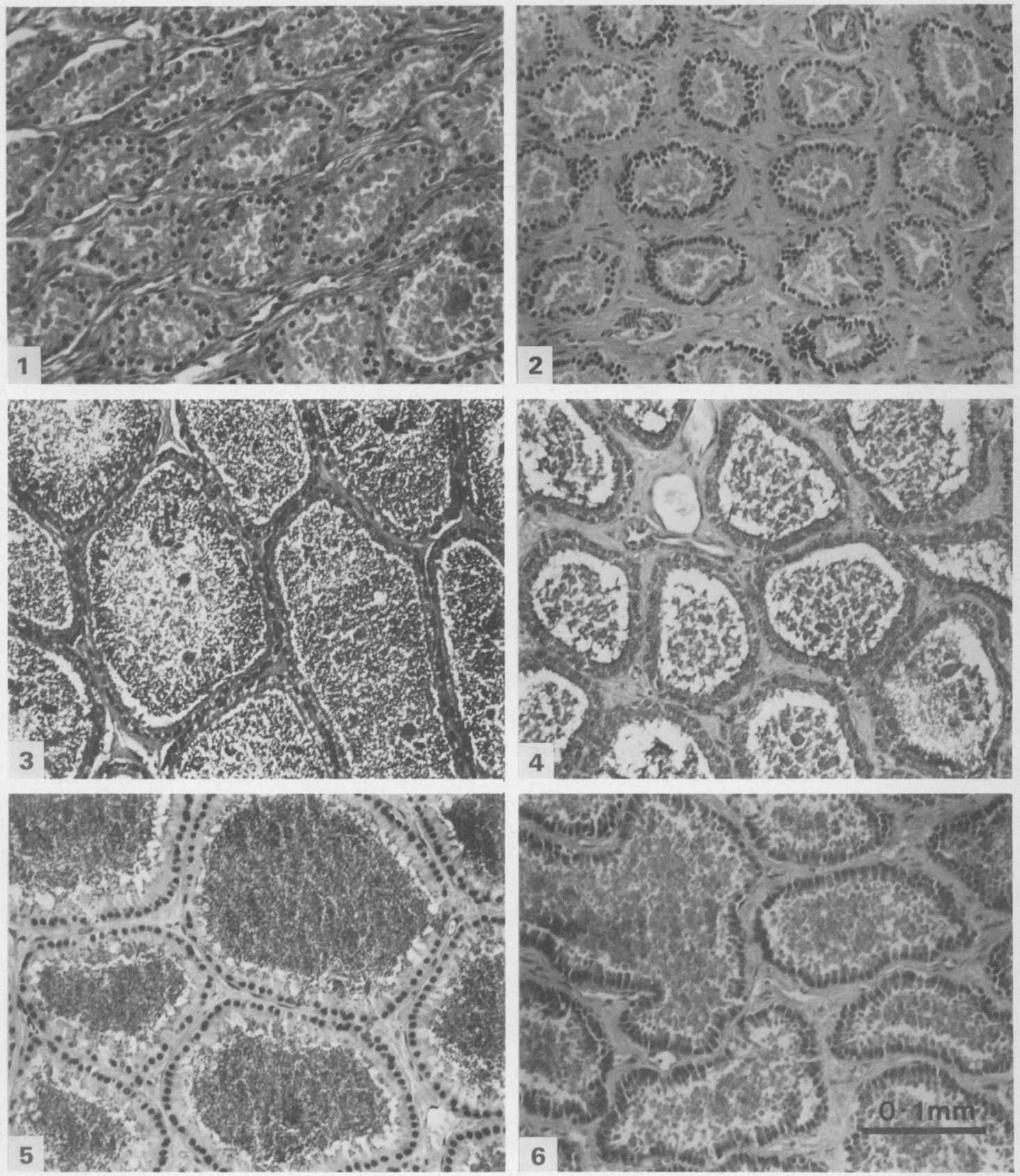

Changes in the histology of the prostate gland of tammar wallabies in the breeding season (Figs 1,3 and 5) and the non-breeding season (Figs 2, 4 and 6). Figs 1 and 2, anterior segment; Figs 3 and 4, the central segment: and Figs 5 and 6 the posterior segment. 
ducts. The glands consist of numerous tubules, lined with columnar epithelium, and surrounded by a striated muscle coat. The Cowper's glands were not separated but weighed as one structure. There was a significant seasonal change in weight $(P<0.001)$ (Text-fig. 2$)$ similar to that shown by the prostate gland.

Only the largest of the Cowper's glands was examined histologically. It showed changes similar to those of the prostate gland in that the tubules were larger in cross-section in the breeding season. Mucopolysaccharides were present throughout the year.

Despite the large variation between animals the mean concentration of testosterone was elevated in the breeding season (Text-fig. 2).

There was a significant correlation $(r=0.562, P<0.01, \mathrm{~N}=20)$ between prostate gland weight (in the breeding season), $x$, and testosterone concentration, $y(y=0.098 x-1.284)$.

\section{Discussion}

The results show that male tammar wallabies in the wild did not have a seasonal cycle in the weight of the testes or epididymides, and that spermatozoa were present throughout the year. However, an increase in the size of the accessory reproductive organs and in plasma testosterone concentration was observed during the breeding season. Catt (1977) found a similar increase in the size of the prostate gland in Bennett's wallaby (Macropus rufogriseus fruticus), a species with a reproductive pattern similar to that of the tammar. The significant correlation between plasma testosterone levels and the size of the prostate gland in the tammar suggests that the increase in size of the accessory reproductive organs is due to the action of this hormone. Cook, McDonald \& Gibson (1978) found a similar relationship between prostate gland size and plasma androgen levels in the brush-tailed possum. They postulated that transfer of androgens into prostatic tissue from the fluid contents of the urethra could occur via the surrounding vascular complex.

Hearn (1975) observed that in captive tammars hypophysectomy resulted in a fall in gonadotrophin levels and subsequent decline in weight of the testes and accessory sex organs, indicating that maintenance of the reproductive system is pituitary dependent. Catling \& Sutherland (1980) also measured gonadotrophin levels in captive tammars but they divided their animals into two groups. One group had access to sexually mature females while the other group was isolated from females. Over the breeding season no changes in FSH, LH or testosterone levels were observed in the isolated group but there was a marked rise in $\mathrm{LH}$ and testosterone in the animals in contact with females. Lincoln (1978) has demonstrated that injection of LH-RH can induce a rapid and substantial increase in plasma testosterone levels in 5 species of macropodids, including the tammar wallaby. Furthermore, macropodid marsupials do possess distinct LH and FSH receptors in the testis (Stewart, Sutherland \& Tyndale-Biscoe, 1981).

Thus, for the male tammar wallaby in the breeding season, release of LH-RH from the hypothalamus would stimulate the anterior pituitary to increase LH levels and LH then acts on the testis to induce secretion of testosterone which causes the increase in size and activity of the accessory reproductive organs. Testicular function is maintained throughout the year by the constant level of FSH released from the pituitary. Catling \& Sutherland (1980) observed that the levels of LH and testosterone rose at least 2 weeks before mating began, suggesting that a female pheromone is responsible for activating the reproductive system of the male.

The breeding cycle of the female tammar wallaby is under photoperiodic control (Sadleir \& Tyndale-Biscoe, 1977; Tyndale-Biscoe, 1980) but it is evident that the male responds only to the reproductive condition of the female. In many seasonally breeding eutherian mammals the males and females respond to environmental cues, the males having a cycle of testicular enlargement and regression (Amoroso \& Marshall, 1960). Amongst the seasonally breeding marsupials, both types of reproductive pattern can be found. The ring-tail possum (Pseudocheirus peregrinus) and the greater 
glider (Schoinobates volans) both show regression in the size of the testes during the non-breeding season (Hughes, Thomson \& Owen, 1965; Smith, 1969). However the brush-tailed possum and Bennett's wallaby, like the tammar, do not show any changes in testicular size throughout the year (Gilmore, 1969; Catt, 1977). It is possible that a seasonal breeding pattern of the latter type is a relatively recent development, related to climatic changes or expansion of populations into new environments.

I thank Dr S. Barker for supervision of this study and critically reading the manuscript; Dr C. H. Tyndale-Biscoe for useful criticisms; Ray Bickle, Leon Hall, Stephen McKillup and Graham Warncken for help collecting animals; Ms Meg Ralph for the radioimmunoassay, and various other people who have assisted me.

\section{References}

Amoroso, E.C. \& Marshall, F.H.A. (1960) External factors in sexual periodicity. In Marshall's Physiology of Reproduction, 3rd edn, Vol. 1, pp. 707-831. Ed. A. S. Parkes. Longmans Green, London.

Andrewartha, H.G. \& Barker, S. (1969) Introduction to a study of the ecology of the Kangaroo Island Wallaby, Protemnodon eugenii (Desmarest), within Flinders Chase, Kangaroo Island, South Australia. Trans. $R$. Soc. S. Aust. 93, 127-132.

Berger, P.J. (1966) Eleven-month 'embryonic diapause' in a marsupial. Nature, Lond. 211, 435-436.

Berger, P.J. \& Sharman, G.B. (1969) Embryonic diapause initiated without the suckling stimulus in the wallaby, Macropus eugenii. J. Mammal. 50, 630-632.

Biggers, J.D. (1966) Reproduction in male marsupials. Symp. zool. Soc. Lond. 15, 353-363.

Catling, P.C. \& Sutherland, R.L. (1980) Effect of gonadectomy, season, and the presence of females on plasma testosterone, luteinizing hormone, and follicle-stimulating hormone levels in male tammar wallabies (Macropus eugenii). J. Endocr. 86, 25-33.

Catt, D.C. (1977) The breeding biology of Bennett's wallaby (Macropus rufogriseus fruticus) in South Canterbury, New Zealand. N. Z. J. Zool. 4, 401-411.

Cook, B., McDonald, I.R. \& Gibson, W.R. (1978) Prostatic function in the brush-tailed possum, Trichosurus vulpecula. J. Reprod. Fert. 53, 369-375.

Drury, R.A.B. \& Wallington, E.A. (1967) Carleton's Histological Technique, 4th edn. Oxford University Press, London.

Frith, H.J. \& Sharman, G.B. (1964) Breeding in wild populations of the red kangaroo, Megaleia rufa. C.S.I.R.O. Wildl. Res. 9, 86-114.

Gilmore, D.P. (1969) Seasonal reproductive periodicity in the male Australian brush-tailed possum (Trichosurus vulpecula). J. Zool., Lond. 157, 75-98.

Hearn, J.P. (1975) The role of the pituitary in the reproduction of the male Tammar wallaby, Macropus eugenii. J. Reprod. Fert. 42, 399-402.

Hughes, R.L., Thomson, J.A. \& Owen, W.H. (1965) Reproduction in natural populations of the Australian ringtail possum, Pseudocheirus peregrimus (Marsupialia: Phalangeridae), in Victoria. Aust. J. Zool. 13, 383-406.

Inns, R.W. (1982) Age determination in the Kangaroo Island wallaby, Macropus eugenii (Desmarest). Aust. Wildl. Res. 9, 213-220.
Lincoln, G.A. (1978) Plasma testosterone profiles in male macropodid marsupials. $J$. Endocr. 77, 347-351.

Newsome, A.E. (1965) Reproduction in natural populations of the red kangaroo, Megaleia rufa (Desmarest), in central Australia. Aust. J. Zool. 13, 735759.

Rodger, J.C. (1978) Male reproduction-its usefulness in discussions of Macropodidae evolution. Aust. Mammal. 2, 73-80.

Rodger, J.C. \& Hughes, R.L. (1973) Studies of the accessory glands of male marsupials. Aust. J. Zool. 21, 303320.

Sadleir, R.M.F.S. (1965) Reproduction in two species of kangaroo Macropus robustus and Megaleia rufa in the arid Pilbara region of Western Australia. Proc. zool. Soc. Lond. 145, 239-261.

Sadleir, R.M.F.S. \& Tyndale-Biscoe, C.H. (1977) Photoperiod and the termination of embryonic diapause in the marsupial Macropus eugenii. Biol. Reprod. 16, 605-608

Setchell, B.P. (1977) Reproduction in male marsupials. In The Biology of Marsupials, pp. 411-455. Eds B. Stonehouse \& D. Gilmore. Macmillan, London.

Setchell, B.P. \& Carrick, F.N. (1973) Spermatogenesis in some Australian marsupials. Aust. J. Zool. 21, 491 499.

Sharman, G.B. \& Berger, P.J. (1969) Embryonic diapause in Marsupials. Adv. Reprod. Physiol. 4, 211240.

Smith, R.F.C. (1969) Studies on the marsupial glider, Schoinobates volans (Kerr) 1. Reproduction. Aust. J. Zool. 17, 625-636.

Stewart, F., Sutherland, R.L. \& Tyndale-Biscoe, C.H. (1981) Macropodid marsupial testicular gonadotrophin receptors and their use in assays for marsupial gonadotrophins. $J$. Endocr. 89, 213-223.

Tyndale-Biscoe, C.H. (1980) Photoperiod and the control of seasonal reproduction in marsupials. In Endocrinology 1980, pp. 277-282. Eds I. A. Cumming, J. W. Funder \& F. A. O. Mendelsohn. Aust. Acad. Sci., Canberra.

Tyndale-Biscoe, C.H., Heam, J.P. \& Renfree, M.B. (1974) Control of reproduction in macropodid marsupials. J. Endocr. 63, 589-614. 